\title{
Rapid detection of Mycobacterium tuberculosis DNA and genetic markers for Isoniazid resistance in Ziehl-Neelsen stained slides
}

\author{
Graziele Lima Bello ${ }^{1 /+}$, Franciele Costa Leite Morais ${ }^{1}$, Sheile Pinheiro de Jesus ${ }^{1}$, \\ Jonas Michel Wolf', Mirela Gehlen², Isabela Neves de Almeida ${ }^{3}$, Lida Jouca de Assis Figueiredo ${ }^{3}$, \\ Tainá dos Santos Soares ${ }^{4}$, Regina Bones Barcellos ${ }^{5,6}$, Elis Regina Dalla Costa ${ }^{6,7}$, \\ Silvana Spíndola de Miranda ${ }^{3}$, Maria Lucia Rosa Rossetti ${ }^{1,4,5,6}$
}

1Universidade Luterana do Brasil, Programa de Pós-Graduação em Biologia Celular e Molecular Aplicada à Saúde, Canoas, RS, Brasil
2Universidade Federal do Rio Grande do Sul, Programa de Pós-Graduação em Pneumologia, Porto Alegre, RS, Brasil
${ }^{3}$ Universidade Federal de Minas Gerais, Faculdade de Medicina, Laboratório de Pesquisa em Micobactérias, Belo Horizonte, MG, Brasil
${ }^{4}$ Universidade Luterana do Brasil, Graduação em Biomedicina, Canoas, RS, Brasil
${ }^{5}$ Secretaria do Estado do Rio Grande do Sul, Centro de Desenvolvimento Científico e Tecnológico, Porto Alegre, RS, Brasil
${ }^{6}$ Universidade Federal do Rio de Janeiro, Programa de Pós-Graduação em Clínica Médica, Rio de Janeiro, RJ, Brasil
${ }^{7}$ AstraZeneca do Brasil, Cotia, SP, Brasil

BACKGROUND Early diagnosis of tuberculosis (TB) and identification of strains of Mycobacterium tuberculosis resistant to antiTB drugs are considered the main factors for disease control.

OBJECTIVES To standardise a real-time polymerase chain reaction (qPCR) assay technique and apply it to identify mutations involved in M. tuberculosis resistance to Isoniazid (INH) directly in Ziehl-Neelsen (ZN) stained slides.

METHODS Were analysed 55 independent DNA samples extracted from clinical isolates of $M$. tuberculosis by sequencing. For application in TB diagnosis resistance, $59 \mathrm{ZN}$-stained slides were used. The sensitivity, specificity and Kappa index, with a $95 \%$ confidence interval (CI95\%), were determined.

FINDINGS The agreement between the tests was, for the $k a t G$ target, the Kappa index of 0.89 (CI95\%: 0.7-1.0). The sensitivity and specificity were 97.6\% (CI95\%: 87.7-99.9) and 91.7\% (CI95\%: 61.5-99.5), respectively. For inhA, the Kappa index was 0.92 (CI95\%: $0.8-1.0$ ), the sensitivity and specificity were $94.4 \%$ (CI95\%: 72.7-99.8) and 97.3\% (CI95\%: 85.8-99.9), respectively. The use of ZNstained slides for drug-resistant TB detection showed significant results when compared to other standard tests for drug resistance.

MAIN CONCLUSIONS qPCR genotyping proved to be an efficient method to detect genes that confer M. tuberculosis resistance to INH. Thus, qPCR genotyping may be an alternative instead of sequencing.

Key words: Mycobacterium tuberculosis - Isoniazid resistance - genotyping - real-time PCR

Drug-resistant and multidrug-resistant tuberculosis (DR/MDR-TB) has increased worldwide, demanding the development of new drug resistance detection assays. The main drugs used in the first-line treatment of TB are Isoniazid (INH) and Rifampicin (RIF) and resistance to both drugs means MDR-TB. Until recently, RIF was considered a marker of MDR-TB, because frequently that resistance is associated with INH resistance. There have been recurrent studies showing the agent Mycobacterium tuberculosis resistant to INH and sensitive to RIF; meaning a risk factor for unfavorable outcomes. ${ }^{(1)}$

Globally, monoresistance to INH presented in 2014 an overall mean of $9.5 \%$ in new cases and $14 \%$ in previously treated TB. It is estimated that more than 1 million people develop INH resistant, each year. ${ }^{(2)}$ Nevertheless, routine tests for INH resistance are not used as frontline

doi: 10.1590/0074-02760190407

GB and JMW were supported by CAPES (MEC/Brazil-Fellowship. Financing code 001).

+ Corresponding author: grazilbello@gmail.com

(D) https://orcid.org/0000-0001-8537-8413

Received 31 October 2019

Accepted 06 March 2020 tests in most scenarios. ${ }^{(3)}$ In Brazil, the most used test for the rapid screening of TB drug resistance (at main health centres) is the Gene Xpert MTB/RIF, however, it only detects resistance to RIF. Commercial molecular hybridisation tests to detection INH resistance, such as GenoType MTBDRplus ${ }^{\circledR}$ line probe assays (Hain Lifescience, Nehren, Germany), are sensitive and specific, but, in Brazil, only a few sites use it routinely and the clinical impact of this test has not been evaluated. ${ }^{(4)}$

Resistance to INH is associated with a wide variety of mutations that affects one or more genes, such as katG, inh $A$, ahpC genes. In general, mutations in kat $G$ and inh $A$ genes are found in $75-85 \%$ of the isolates resistant to this drug. ${ }^{(5)}$ The most common mutation in the katG gene arises at codon 315 by replacing the serine amino acid (AGC) to threonine (ACC), with a decrease in the action of catalase, important for activating the drug. ${ }^{(6)}$ In several studies around the world, the frequency of INH resistant strains varies from 50 to $100 \%$ with the mutation at codon 315 of the kat $G$ gene. ${ }^{(7)}$ The inhA gene encodes the enoyl-ACP reductase (NADH) fatty acid carrier protein, which is essential in the synthesis of mycolic acids in the cell wall of the bacterium. The mutation of the inhA gene modifies the enzyme, which loses affinity for NADH, resulting in resistance to INH. ${ }^{(8)}$ 
One of the limitations of performing molecular tests is the safe storage and transportation of sputum samples (potentially infectious) from remote health centres to central laboratories. In addition, the high cost and proper transportation logistics for this type of sample, as well as the return of test results to the source laboratory and to the patient can also be a challenge. In view of this, $\mathrm{ZN}$-stained slides (which is the first test commonly performed in most peripheral-level laboratories and health centres in low-income countries), would be readily available and could be the ideal tool for safe system transportation of sputum, analysis of molecular tests and therefore timely management of TB patients..$^{(9)}$

Thus, in the face of the need for further studies on the identification of resistance to INH and the development more cost-effective technologies, this study aimed to standardise and identify mutations involved with $M$. tuberculosis INH resistance by real-time polymerase chain reaction (qPCR) genotyping assays, using DNA extracted from clinical isolates (standardisation) e smear slides samples (application in TB diagnosis resistance).

\section{MATERIALS AND METHODS}

Standardisation of TaqMan ${ }^{\circledR}$ qPCR genotyping assays to the detection of INH resistance in culture of $M$. tuberculosis - This study was performed using a total of 55 independent DNA samples extracted from clinical isolates of M. tuberculosis, according to described by Van Soolingen et al., ${ }^{(10)}$ Samples were stored at $-80^{\circ} \mathrm{C}$ in the Molecular Biology Laboratory, at the Centre for Scientific and Technological Development (CDCT) of the State Health Secretariat (SES), located in the city of Porto Alegre, Southern Brazil. These DNA samples were already characterised by the sequencing of genes regions involved with INH resistance).(7) DNA was quantified by spectrophotometry using the SpectraMaxPlus ${ }^{\circledR}$ (Eppendorf) spectrophotometer according to the manufacturer's instructions. The concentrations of 100, 50, 20 and 10 $\mathrm{ng} / \mu \mathrm{L}$ were evaluated. The amplifications that showed fluorescence signals with sigmoidal curves plus detection characteristics by qPCR were the samples quantified with a final DNA concentration of $20 \mathrm{ng} / \mu \mathrm{L}$. This final concentration was ideal for qPCR identification.

Previously, all the 55 isolates used in the present study were confirmed as containing acid-fast bacilli by microscopy detection on ZN-stained slides. ${ }^{(11)}$ Standard bacteriological and biochemical tests were performed for differentiation of species within the M. tuberculosis complex (MTBC) and Mycobacteria other than tuberculosis (MOTT), including biochemical testing for niacin, paranitrobenoic acid (PNB) and tiofeno-2-carboxylic acid hydrazine (TCH) ${ }^{(11)}$ Subsequently, the isolates were submitted to drug susceptibility testing (DST) using the Bactec $^{\mathrm{TM}-}$ MGIT $^{\text {TM}} 960$ system, according to the manufacturer. ${ }^{(12)}$

Application of TaqMan ${ }^{\circledR}$ qPCR genotyping assays to the detection of INH resistance in DNA extracted from Ziehl-Neelsen stained slides - For the application of qPCR assays in clinical samples, 59 smear slides were used from the Mycobacterial Laboratory, School of Medicine, Federal University of Minas Gerais (UFMG/ Brazil). These specimens had the following tests: spu- tum smear microscopy $(\mathrm{ZN})$, solid mycobacterial culture from Lowestein Jensen, phenotypic species identification tests, anti-TB drug tests, ${ }^{(11)}$ GeneXpert MTB/RIF, ${ }^{(13)}$ and GenoType MTBDRplus ${ }^{\circledR}$ - Hain Tape. ${ }^{(14)}$ DNA extraction from slides was performed using 5\% Chelex from a protocol adapted from Van Der Zanden, ${ }^{(15)}$ as follows: $100 \mu \mathrm{L}$ of ultrapure water was added over the smear slide to facilitate detachment of the sample; then a clean slide was used to scrape the material. This was transferred to another microtube, where the 5\% Chelex reagent solution was subsequently added. The samples were then incubated in a thermoblock at $56^{\circ} \mathrm{C}$ for $30 \mathrm{~min}$ and then at $100^{\circ} \mathrm{C}$ for $10 \mathrm{~min}$ for cell lysis. The microtubes were centrifuged at 14,000 rpm for $15 \mathrm{~min}$, and the supernatant was transferred to another microtube. To improve the quality, each DNA sample was subjected to a purification step using silica columns and washed with specific buffers (adapted from Boom et al.). ${ }^{16}$

Real-time PCR - The qPCR analysis was performed using in a StepOne Real-time PCR System (AB Applied Biosystems) and the amplified products were detected by the TaqMan ${ }^{\circledR}$ detection system (AB Applied Biosystems). The reaction was standardised in a total volume of $20 \mu \mathrm{L}$, containing $10 \mu \mathrm{L}$ of the kapa master mix, $1 \mu \mathrm{L}$ of primers solution and probes (AB Applied Biosystems) at a concentration of $20 \mathrm{X} .2 \mu \mathrm{L}(10 \mathrm{ng} / \mathrm{uL})$ of DNA was added in the mix. The control used as wild type (WT) profile (for both genes) was the DNA of the M. tuberculosis $\mathrm{H} 37 \mathrm{Rv}$ reference strain. As a negative reaction control, the PCR mix containing nucleus-free ultrapure water was used. Amplification conditions were activation of the enzyme at $95^{\circ} \mathrm{C}$ for $10 \mathrm{~min}$ (heating stage), 40 cycles of denaturation at $95^{\circ} \mathrm{C}$ for $15 \mathrm{~s}$ and annealing and extension at $60^{\circ} \mathrm{C}$ for $1 \mathrm{~min}$. There were pre-PCR and post-PCR steps of $60^{\circ} \mathrm{C}$ for $30 \mathrm{~s}$. These assays for detection of gene target polymorphisms have been customised by Applied Biosystems/Thermo Fisher Scientific (4332077-Custom TaqMan SNP genotyping assays non-human, SM). Large sequences of "base" fragments corresponding to the target regions used for identification of INH resistant M. tuberculosis ( $k a t G 315 \mathrm{G} / \mathrm{C}$ and $\operatorname{inh} A-15 \mathrm{C} / \mathrm{T}$ ) were sent for the synthesis of the assays. The analysis of the results was performed with a tool offered by the manufacturer: Thermo Fisher Cloud (https://www.thermofisher.com/search/results?query=c loud \&focusarea $=$ Search $\% 20$ All), which provides more options for the evaluation of the results.

Statistical analyses - Data were analysed using the Statistical Package for Social Sciences (SPSS, version 23.0, Chicago, IL). To evaluate the agreement between the results of the tests performed, the Kappa index was calculated (in pairs). The sensitivity, specificity, Kappa index and receiver operating characteristic (ROC) curve for the analysis of the accuracy level of the genotyping tests, with a $95 \%$ confidence interval, were also evaluated.

Ethical aspects - This study was approved by the research ethics committee of the School of Public Health/ Health Department ESP/SES/RS (approval number: 1.607.182) and Federal University of Minas Gerais (number: CAAE: 02232412.7.1001.5149). 


\section{RESULTS}

Standardisation procedures - The genotypic profile obtained by sequencing characterised the samples in $9.11 \%$ [(5/55); WT (katG)/MUT (inhA)], 12.72\% [(7/55); WT (katG)/WT (inhA)], 52.72\% [(29/55); MUT (katG)/WT (inhA)] and 25.45\% [(14/55); MUT (katG)/MUT (inhA)].

Genotyping of kat $G$ gene $(315 \mathrm{G} / \mathrm{C})$ - Of the 55 DNAs extracted from INH resistant cultures, 43 mutated (MUT) and 12 WT were detected in the region of the gene, according to the characterisation by sequencing. Genotyping by qPCR detected 42 MUT (42/43) and 11 WT (11/12) samples. The agreement value of the Kappa index was 0.89 (CI95\%: 0.7-1.0) (agreement considered excellent according to the classification quality). The sensitivity and specificity were $97.6 \%$ (CI95\%: 87.7-99.9) and $91.7 \%$ (CI95\%: 61.5-99.5), respectively (Table I). In the detection graphs, the analysis of the curves allows us to evaluate the genotypic profile of each template, as well as to discriminate the distribution of the clusters [see Supplementary data (Fig. 1)]. The ROC curve was used to evaluate the sensitivity (or rate of true positives) versus specificity (false positive rate), in the other words, it is the representation of a visual index of the accuracy of the assay [see Supplementary data (Fig. 2)]. The area under the curve, which is a statistical summary for the determination of the level of test accuracy, was $0.94($ reference $=1.0)$.

Genotyping of inhA gene (-15 C/T) - As from 55 extracted DNAs, the sequencing identified 18 MUT and 37 WT samples. Genotyping by qPCR assay identified 17 MUT and 36 WT samples (one discordant sample for each profile). The value of the Kappa index was 0.92 (C195\%: 0.8-1.0) (agreement considered excellent). Sensitivity and specificity were $94.4 \%$ (CI95\%: 72.7-99.8) and 97.3\% (CI95\%: 85.8-99.9), respectively (Table I). Fig. 3, in Supplementary data, shows the plots from the genotyping experiments. The ROC curve [see Supplementary data (Fig. 4)] showed test accuracy (area under curve) of 0.96 (reference $=1.0$ ). As genotyping for the previous target, the inh $A$ target exhibited consistent performance.
$F N$-stained slides - All negative smear slides were culture-matched, as well as with GeneXpert MTB/RIF (TRM - Rapid Molecular Test). The qPCR detected (from the negative smear slides and culture) a WT profile sample for both genes studied. The agreement of qPCR with negative culture was $96.7 \%$. On smear-positive slides that also had a positive culture test, the DST and the GenoType MTBDRplus ${ }^{\circledR}$ were performed. The first test is based on phenotypic identification and the second, on gene analysis, therefore, in DST, only antimicrobial resistance (INH) can be analysed. A comparison of gene analysis is only possible when comparing qPCR versus GenoType MTBDR $p l u s^{\circledR}$. The Kappa index for the agreement between the last two tests cited (valid cases) in relation to the $k a t G$ and $i n h A$ genes was 0.82 and 1 , respectively. If we compare the samples for INH drug sensitivity and resistance (DST) versus GenoType MTBDRplus ${ }^{\circledR} / \mathrm{qPCR}$ ), the obtained Kappa indices were 0.69 and 0.25 , respectively [see Supplementary data (s 5, 6, 7)].

A comparison was also performed between the positive FN-stained slides quantified as + (1 to 10 bacilli by field in 50 observed fields), ++ (10 to 99 bacilli in 100 observed fields), +++ (on average more than 10 bacilli by field in 20 observed fields), 1 to 9 bacilli in 100 observed fields) ${ }^{(1)}$ and the threshold cycling (Cts) discriminated by qPCR (Table II). In some cases, the smear slides that had the most bacilli in observed fields, had lower Cts, in others [slide 10, 11 and 18 (Table II)], there was not the same agreement. The microscopy of the $\mathrm{ZN}$-stained slides [slide 1 (Table II)] did not reveal acid-fast bacilli, although the sample contained in the slide provided sufficient DNA for amplification by qPCR identification.

\section{DISCUSSION}

Monoresistance to INH has become increasingly common over the years. Studies have found high rates of resistance for this drug, and there is still no consensus on how patients can be treated. Furthermore, the treatment outcome is most likely unfavorable and failure to identify an INH-resistant isolate is equivalent to losing the efficacy of one of the drugs and compromising the basic

TABLE I

Performance of $k a t G$ and $i n h A$ genes genotyping by real-time polymerase chain reaction (qPCR) in clinical isolates

\begin{tabular}{lcccccc}
\hline Assay & $\begin{array}{c}\text { Sequencing } \\
(\text { MUT })\end{array}$ & $\begin{array}{c}\text { Sequencing } \\
(\text { WT })\end{array}$ & Total & $\begin{array}{c}\text { Sensitivity } \\
(\text { CI 95\%) }\end{array}$ & $\begin{array}{c}\text { Specificity (CI } \\
95 \%)\end{array}$ & $\begin{array}{c}\text { Kappa index } \\
\text { (CI 95\%) }\end{array}$ \\
\hline qPCR katG (MUT) & 42 & 1 & 43 & 97.6 & 91.7 & 0.89 \\
\hline qPCR katG $($ WT) & 1 & 11 & 12 & $(87.7-99.9)$ & $(61.5-99.7)$ & $(0.7-1.0)$ \\
\hline Total & 43 & 12 & 55 & & & \\
\hline qPCR inhA (MUT) & 17 & 1 & 18 & 94.4 & 97.3 & 0.92 \\
\hline qPCR inhA (WT) & 1 & 36 & 37 & $(72.7-99.8)$ & $(85.8-99.9)$ & $(0.8-1.0)$ \\
\hline Total & 18 & 37 & 55 & & & \\
\hline
\end{tabular}

CI: confidence interval; MUT: mutated; WT: wild type. 
TABLE II

Comparison between the Ziehl-Neelsen (ZN)-stained slides classification and the threshold cycling (Cts) detected samples by real-time polymerase chain reaction (qPCR) assays

\begin{tabular}{|c|c|c|c|}
\hline Samples & ZN slides & qPCR (Cts katG) & qPCR (Cts inhA) \\
\hline 1 & NEG & WT (31.01) & WT (30.84) \\
\hline 2 & ++ & WT (32.35) & WT (35.90) \\
\hline 3 & + & WT (33.20) & WT (33.64) \\
\hline 4 & 3 BACILLI / 100 FIELDS. & UNDETERMINED & UNDETERMINED \\
\hline 5 & 3 BACILLI / 100 FIELDS. & UNDETERMINED & UNDETERMINED \\
\hline 6 & +++ & WT (32.35) & WT (35.53) \\
\hline 7 & 3 BACILLI / 100 FIELDS. & WT (35.23) & WT (35.15) \\
\hline 8 & +++ & WT (28.06) & WT (28.41) \\
\hline 9 & 3 BACILLI / 100 FIELDS. & UNDETERMINED & UNDETERMINED \\
\hline 10 & + & WT (33.19) & WT (32.55) \\
\hline 11 & ++ & WT (36.27) & WT (36.99) \\
\hline 12 & ++ & UNDETERMINED & UNDETERMINED \\
\hline 13 & + & WT (37.89) & WT (36.95) \\
\hline 14 & + & WT (32.28) & WT (32.01) \\
\hline 15 & + & WT (32.89) & WT (35.54) \\
\hline 16 & + & MUT (29.81) & WT (30.53) \\
\hline 17 & +++ & WT (36.57) & WT (36.20) \\
\hline 18 & +++ & WT (33.96) & WT (36.16) \\
\hline 19 & 4 BACILLI / 100 FIELDS. & WT (32.72) & WT (35.91) \\
\hline 20 & + & WT (33.46) & WT (34.61) \\
\hline 21 & + & MUT (33.95) & WT (36.00) \\
\hline 22 & +++ & WT (32.81) & WT (34.29) \\
\hline \multirow[t]{3}{*}{23} & +++ & WT (32.15) & WT (33.01) \\
\hline & & WT $(33.79 \pm 2.33)$ & WT $(35.71 \pm 0.84)$ \\
\hline & & MUT $(31.88 \pm 2.92)$ & - \\
\hline
\end{tabular}

NEG: negative; MUT: mutated; WT: wild type; +: 10 to 99 bacilli in 100 observed fields; ++: 1 to 10 bacilli by field in 50 observed fields; +++: on average more than 10 bacilli by field in 20 observed fields. 1 to 9 bacilli in 100 observed fields. Median \pm standard deviation.

regimen of treatment. ${ }^{(17)}$ The lack of adequate treatment to combat an INH resistant isolate could also be inducing gene-level changes (mutations), generating MDR clones, since resistance to RIF comes in sequence. ${ }^{(2)}$ The qPCR assays performed in this study identified the most known mutations in genetic regions associated with INH resistance (katG $315 \mathrm{G} / \mathrm{C}$ and inhA $-15 \mathrm{C} / \mathrm{T}$; GenBank: (MG995339, MG995338, MG995265 e CP023597 - National Centre for Biotechnology Information - NCBI https: //www.ncbi. nlm.nih.gov/genbank/). It is important to consider that the mutations associated with INH are more complex and occur in many M. tuberculosis genes. However, the most used genes as markers, according to studies, such as a recent systematic review (Seifert et al.), ${ }^{(18)}$ which evaluated $11.411 \mathrm{M}$. tuberculosis isolates in 49 countries (January 2000 to August 2013), are the katG $(315 \mathrm{G} / \mathrm{C})$ and the inhA $(-15 \mathrm{C} / \mathrm{T})$ promoter region. Confirming these findings, we also have the study of Monteserin et al., ${ }^{(19)}$ who evaluated the same markers to analyse the drug resistance profile of INH and the distribution of clusters in Argentina, as well as the study of
Lopez-Avalos et al., ${ }^{(20)}$ which used the same markers to identify the resistance already described.

Regarding the agreement of the standardisation results, the sensitivity, specificity, Kappa index and ROC curve are evaluated in most of the studies that use the analysis of diagnostic tests and/or comparison of results between techniques (GeneXpert MTB/RIF, GeneXpert MTB/RIF Ultra, Genotype MTBDRplus, TB-SPRINT, and others). ${ }^{(21)}$ Concerning the discrepancies in the agreement of the tests, we believe that it is due to the alternative molecular mechanisms of resistance, many of which are still unknown, or even that they present a rare genotypic profile, found in a few strains of the M. tuberculosis complex. ${ }^{(22)}$ Another important bias to consider is that some tests have different detection methods, such as DST and GeneXpert MTB/RIF (microbiological versus molecular detection), therefore, some comparisons allowed statistical calculations with greater equity, but others had more restricted analyses to the detection method. ${ }^{(21,23)}$

With regard to the diagnosis of drug-resistant TB in clinical sputum samples, it is known that in low-income 
countries there are frequent obstacles in transporting and storing samples from peripheral regions to reference laboratories performing molecular analyses, restricting surveillance and the population of the real scenario of the disease. ${ }^{(24)}$ Facing this situation and based on the literature, smear microscopy slides (first test most commonly used for screen for pulmonary TB; culture and DST methods are not routinely used as they require more modern equipment and larger biosafety structure, that are only available from reference laboratories) can be a safe way to transport sputum samples from peripheral sites to central laboratories that perform molecular tests for $\mathrm{TB}$, increasing the speed of diagnosis and promoting better patient management. ( $^{(9)}$

Thus, we showed that DNA extracts from $\mathrm{ZN}$-stained slides may be used as a template for the amplification of M. tuberculosis DNA by qPCR technique. Similar results were also obtained by Gonçalves et al., ${ }^{(25)}$ who used the same DNA extraction technique for detection by qPCR assays. De Almeida et al., ${ }^{(26)}$ evaluated six different techniques for $M$. tuberculosis DNA extraction, including DNA extraction by Chelex from cultures of microorganism and FN-stained slides. One of the results obtained was that the method using the Chelex + NP40 for DNA extraction reagents provided an adequate amount of interference-free DNA. Thus, according to the Rakotosamimanana et al ${ }^{(9)}$ results, our study allowed the use of smear slides as a source of DNA extraction for the diagnosis of TB and to perform some additional analyses for drug resistance evaluation.

Smear microscopy slides are known to be simple, fast and less costly for the initial diagnosis of TB, however, sensitivity and specificity still remain low. ${ }^{(27)}$ These measures are also dependent on the quality of the smear performed as well as the training of the microscopy analyser. We found the presence of M. tuberculosis DNA in patient sample 1 (Table II), however, the presence of the bacillus was not visualised on microscopy. ${ }^{(28)} \mathrm{Com}-$ bining the FN-stained slide with bacillus DNA detection and drug resistance testing increases the effectiveness of the analyses and makes them more cost-effective. ${ }^{(27)}$

Evaluating the results, genotyping analyses in $M$. tuberculosis strains could contribute significantly to disease control, indicate possible epidemiological associations, detect suspicious outbreak information and cross-contamination in laboratories, and even distinguish between reinfections exogenous and endogenous reactivation during retreatment. ${ }^{(29)}$ Although the use of sequencing is considered the gold standard for resistance detection, recent studies have shown that the use of qPCR genotyping is widely used in molecular diagnostics as well as in resistance profile identification studies due to its specificity, the high degree of automation and good reproducibility. ${ }^{(30)}$

In the present study, part of the experiments was carried out with DNA extracted from clinical isolates collected from Southern Brazil (standardisation step) and, the other part, performed with DNA extracted from $\mathrm{ZN}$ stained slides collected from Southeast Brazil, used for the application in TB diagnosis resistance. This is the main limitation of this study; however, our findings are important for a better understanding of the diagnosis of patients infected with strains of $M$. tuberculosis resistance to INH. Future studies may consolidate our data, thus allowing better therapeutic management for these patients.

In conclusion - Compared to sequencing, our method showed similar sensitivity and specificity to detect genes that confer $M$. tuberculosis sensitivity or resistance to INH. The results suggest that molecular tests can be used for the rapid detection of drug-resistant TB, as FN-stained slides can be considered an effective tool for facilitating DNA extraction from sputum samples, facilitating, bypassing difficulties such as safe storage and transport of samples, also facilitating the diagnosis of TB in peripheral areas. However, further studies with a larger number of samples are still needed to validate the technique and include in the future another TaqMan ${ }^{\circledR}$ assay for the assessment of resistance to RIF.

\section{ACKNOWLEDGEMENTS}

The authors wish to thank the Postgraduate Program in Cellular and Molecular Biology Applied to Health - Lutheran University of Brazil (ULBRA), Micobacterial Research Laboratory, School of Medicine, Federal University of Minas Gerais (UFMG), Centre for Scientific and Technological Development (CDCT-RS) and staff from Laboratory of Molecular/ULBRA, for funding and technical support.

\section{AUTHORS' CONTRIBUTION}

GLB - Lead author, participating from the experimental phase, results from analysis and scientific writing of the manuscript; FCLM - contributed with the experimental phase of the standardisation steps until the application of the technique in smear slides; MG - contributed to the initial stage of the experiments; SPJ - participated in the experimental stage of application of the technique; JMW - contributed statistical analysis and scientific writing of the manuscript; INA - contributed to the analyses performed at the Federal University of Minas Gerais (Brazil) and the scientific writing of the manuscript; LJAF contributed to the analyses carried out at the Federal University of Minas Gerais (Brazil) and the scientific writing of the manuscript; TSS - contributed to the final stage of the experimental analyses; ERDC - contributed to the scientific writing of the manuscript; RBB - contributed with the experimental phase, results from analysis and scientific writing of the manuscript, as well as the supply of the Mycobacterium tuberculosis strains sample bank for the technique standardisation stage; SSM co-advisor, contributed to the analyses performed at the Federal University of Minas Gerais (Brazil) and the scientific writing of the manuscript, as well as the supply of slides for analysis; MLRR - study advisor, responsible for the elaboration and application of the project, as well as the scientific writing of the manuscript. The authors declare that the research was conducted in the absence of any commercial or financial relationships that could be construed as a potential conflict of interest.

\section{REFERENCES}

1. Garcia-Prats AJ, du Plessis L, Draper HR, Burger A, Seddon JA, Hesseling AC, et al. Outcome of culture-confirmed isoniazidresistant rifampicin- susceptible tuberculosis in children. Int $\mathrm{J}$ Tuberc Lung Dis. 2016; 20(11): 1469-76.

2. Romanowski K, Chiang LY, Roth DZ, Krajden M, Tang P, Cook VJ, et al. Treatment outcomes for isoniazid-resistant tuberculosis under program conditions in British Columbia, Canada. BMC Infect Dis. 2017; 17(1): 604: 1-7. 
3. Dheda K, Gumbo T, Maartens G, Dooley KE, McNemey R, Murray $\mathrm{M}$, et al. The epidemiology, pathogenesis, transmission, diagnosis, and management of multidrug-resistant, extensively drug-resistant, and incurable tuberculosis. Lancet Respir Med. 2017; 5(4): 291-360.

4. Dantas NGT, Suffys PN, Carvalho WDS, Gomes HM, Almeida IN, Figueiredo LJA, et al. Correlation between the BACTEC MGIT 960 culture system with genotype MTBDRplus and TB-SPRINT in multidrug resistant Mycobacterium tuberculosis clinical isolates from Brazil. Mem Inst Oswaldo Cruz. 2017; 112(11): 769-74.

5. Perizzolo PF, Dalla Costa ER, Ribeiro AW, Spies FS, Ribeiro MO, Dias CF, et al. Characteristics of multidrug-resistant Mycobacterium tuberculosis in southern Brazil. Tuberculosis. 2012; 92(1): 56-9.

6. Silva PEA, Palomino JC. Molecular basis and mechanisms of drug resistance in Mycobacterium tuberculosis: classical and new drugs. J Antimicrob Chemother. 2011; 66(7): 1417-30.

7. Dalla Costa ER, Ribeiro MO, Silva MSN, Arnold LS, Rostirolla DC, Cafrune PI, et al. Correlations of mutations in katG, oxyRahpC and inh $A$ genes and in vitro susceptibility in Mycobacterium tuberculosis clinical strains segregated by spoligotype families from tuberculosis prevalent countries in South America. BMC Microbiol. 2009; 9(39): 1-11.

8. Siqueira HR, Freitas FAD, Oliveira DN, Barreto AMW, Dalcomo MP, Albano RM. Resistência do Mycobacterium tuberculosis à isoniazida por mutações em duas regiões diferentes do gene katG. J Bras Pneumol. 2009; 35(8): 773-9.

9. Rakotosamimanana N, Rabodoarivelo MS, Palomino JC, Martin A, Razanamparany VR. Exploring tuberculosis by molecular tests on DNA isolated from smear microscopy slides. Int J Infect Dis. 2017; 56: 248-52.

10. Van Soolingen D, de Haas PE, Haagsma J, Eger T, Hermans PW, Ritacco V, et al. Use of various genetic markers in differentiation of Mycobacterium bovis strains from animals and humans and for studying epidemiology of bovine tuberculosis. J Clin Microbiol. 1994; 32(10): 2425-33.

11. MS/SVS/DVDT - Ministério da Saúde/Secretaria de Vigilância em Saúde. Departamento de Vigilância das Doenças Transmissíveis. Manual de Recomendações para o Controle da tuberculose no Brasil / Ministério da Saúde, Secretaria de Vigilância em Saúde, Departamento de Vigilância das Doenças Transmissíveis. Brasília: Ministério da Saúde; 2018.

12. Siddiqi SH, Rüsch-Gerdes S. For BACTEC ${ }^{\mathrm{TM}}$ MGIT $960^{\mathrm{TM}}$ TB System (Also applicable for Manual MGIT). 2006; July.

13. WHO - World Health Organization. Automated real-time nucleic acid amplification technology for rapid and simultaneous detection of Tuberculosis and drug resistant tuberculosis: policy statement. Available from: http://whqlibdoc.who.int/publications/2011/9789241501545_eng.pdf.

14. Hain Lifescience. Geno Type MTBDR plus ver 2.0 Manual. 2012; $1-14$.

15. Van Der Zanden AG, Te Koppele-Vije EM, Vijaya Bhanu N, Van Soolingen D, Schouls LM. Use of DNA extracts from ZiehlNeelsen-stained slides for molecular detection of rifampin resistance and spoligotyping of Mycobacterium tuberculosis. J Clin Microbiol. 2003; 41(3): 1101-8.

16. Boom R, Sol CJ, Salimans MM, Jansen CL, Wertheim-van Dillen PM, van der Noordaa J. Rapid and simple method for purification of nucleic acids. J Clin Microbiol. 1990; 28(3): 495-503.
17. Esteves LS, Dalla Costa ER, Vasconcellos SEG, Vargas A, Ferreira Junior SLM, Halon ML, et al. Genetic diversity of Mycobacterium tuberculosis isoniazid monoresistant and multidrugresistant in Rio Grande do Sul, a tuberculosis high-burden state in Brazil. Tuberculosis (Edinb). 2018; 110: 36-43.

18. Seifert M, Catanzaro D, Catanzaro A, Rodwell TC. Genetic mutations associated with isoniazid resistance in Mycobacterium tuberculosis: a systematic review. PLoS One. 2015; 10(3): 1-13.

19. Monteserin J, Paul R, Latini C, Simboli N, Yokobori N, Delfederico L, et al. Relation of Mycobacterium tuberculosis mutations at kat $G 315$ and inhA -15 with drug resistance profile, genetic background, and clustering in Argentina. Diagn Microbiol Infect Dis. 2017; 89(3): 197-201.

20. Lopez-Avalos AG, Gonzalez-Palomar G, Lopez-Rodriguez M, Vazquez-Chacon CA, Mora-Aguilera G, Gonzalez-Barrios JA, et al. Genetic diversity of Mycobacterium tuberculosis and transmission associated with first-line drug resistance: a first analysis in Jalisco, Mexico. J Glob Antimicrob Resist. 2017; 11: 90-7.

21. Barcellos RB, de Almeida IN, da Silva EC, Gomes HM, de Assis Figueredo LJ, Halon ML, et al. Multicenter evaluation of TBSPRINT 59-Plex Beamedex®: accuracy and cost analysis. BMC Infect Dis. 2019; 19(1): 1047.

22. Xie YL, Chakrovorty S, Armstrong DT, Hall SL, Via LE, Song T, et al. Evaluation of a rapid molecular drug susceptibility test for tuberculosis. N Engl J Med. 2017; 377(11): 1043-54.

23. Chakravorty S, Simmons AM, Rowneki M, Parmar H, Cao Y, Ryan J, et al. Detection of Mycobacterium tuberculosis and resistance to rifampin in an assay suitable for point-of-care testing. MBio. 2017; 8(4): 1-12.

24. Rabodoarivelo MS, Brandao A, Cergole Novella MC, Bombonatte AG, Imperiale B, Rakotosamimanana N, et al. Detection of multidrug-resistant tuberculosis from stored DNA Samples: a multicenter study. Int J Mycobacteriol. 2018; 7 (1): 40-4.

25. Gonçalves MG, Fukasawa LO, Oliveira RS, Salgado MM, Harrison LH, Shutt KA, et al. Fast test for assessing the susceptibility of Mycobacterium tuberculosis to isoniazid and rifampin by realtime PCR. Mem Inst Oswaldo Cruz. 2012; 107(7): 903-8.

26. de Almeida IN, da Silva Carvalho W, Rossetti ML, Costa ER, de Miranda SS. Evaluation of six different DNA extraction methods for detection of Mycobacterium tuberculosis by means of PCRIS6110: preliminary study. BMC Res Notes. 2013; 6(561): 1-6.

27. Bennedsen J, Thomsen VO, Pfyffer GE, Funke G, Feldmann K, Beneke A, et al. Utility of PCR in diagnosing pulmonary tuberculosis. J Clin Microbiol. 1996; 34(6): 1407-11.

28. Carniel F, Dalla Costa ER, Lima-Bello G, Martins C, Scherer LC, Rossetti ML. Use of conventional PCR and smear microscopy to diagnose pulmonary tuberculosis in the Amazonian rainforest area. Braz J Med Biol Res. 2014; 47(12): 1016-20.

29. Moreno V, Espinoza B, Barley K, Paredes M, Bichara D, Mubayi A, et al. The role of mobility and health disparities on the transmission dynamics of tuberculosis. Theor Biol Med Model. 2017; 14(3): 1-17.

30. Seagar A, Neish B, Laurenson IF. Comparison of two in-house Real-time PCR assays with MTB Q-PCR Alert and GenoType MTBDR plus for the rapid detection of mycobacteria in clinical specimens. J Med Microbiol. 2012; 61(10): 1459-64. 